\title{
An experimental and theoretical study on the crystal structure and elastic properties of $\mathrm{Ta}_{1-\mathrm{x}} \mathrm{O}_{\mathrm{x}}$ coatings
}

\author{
C.F. Almeida Alves ${ }^{\mathrm{a}, \mathrm{c}, *}$, L. Marques ${ }^{\mathrm{b}}$, S. Calderon V. ${ }^{\mathrm{c}}$, P.J. Ferreira ${ }^{\mathrm{c}, \mathrm{d}, \mathrm{e}}$, D. Schneider ${ }^{\mathrm{f}}$, \\ A. Cavaleiro ${ }^{g}$, S. Carvalho ${ }^{a, g}$ \\ ${ }^{\text {a }}$ CFUM-UP, Physics Department, University of Minho, Campus of Azurém, 4800-058 Guimarães, Portugal \\ ${ }^{\mathrm{b}}$ CFUM-UP, Physics Department, University of Minho, Campus of Gualtar, 4710-057 Braga, Portugal \\ ${ }^{\mathrm{c}}$ INL - International Iberian Nanotechnology Laboratory, Av. Mestre José Veiga s/n, 4715-330 Braga, Portugal \\ ${ }^{\mathrm{d}}$ Materials Science and Engineering Program, University of Texas at Austin, Austin, TX 78712, USA \\ ${ }^{\mathrm{e}}$ Mechanical Engineering Department and IDMEC, Instituto Superior Técnico, University of Lisbon, Av. Rovisco Pais, $1049-001$ Lisboa, Portugal \\ ${ }^{\mathrm{f}}$ Fraunhofer Institute for Material and Beam Technology (IWS), D-01277 Dresden, Germany \\ ${ }^{\mathrm{g}}$ SEG-CEMMPRE, Mechanical Engineering Department, University of Coimbra, 3030-788 Coimbra, Portugal
}

\section{A R T I C L E I N F O}

\section{Keywords:}

Tantalum oxide coatings

Magnetron sputtering

Ab-initio

STEM

Elastic modulus

\begin{abstract}
A B S T R A C T
The production of $\mathrm{Ta}_{1-\mathrm{x}} \mathrm{O}_{\mathrm{x}}$ coatings has attracted a lot of attention due to their wide variety of industrial applications. Nonetheless, to properly control the functional properties of these coatings, a good understanding of their structural properties must be achieved. $\mathrm{Ta}_{1-\mathrm{x}} \mathrm{O}_{\mathrm{x}}$ phases have structural similarities since they are formed by the distortion of the body centered cubic (bcc) Ta structure and, therefore, a clear and unequivocal identification of the crystalline phases is not trivial. In this regard, this work proposes a theoretical and experimental study to understand the evolution of the structural and the elastic properties of Ta-based coatings. The coatings were deposited by magnetron sputtering as a function of oxygen content and characterized by EPMA (electron probe microanalysis), XRD (X-ray diffraction), STEM (scanning transmission electron microscopy) and SAW (surface acoustic waves). The results demonstrate the formation of a bcc $\alpha$-Ta phase in the non-reactive Ta coating, which transitions to a mixture of crystalline tantalum and tantalum oxide phases for low oxygen concentrations while amorphous phases are observed for high oxygen levels. Ab-initio calculations of different Ta-O phases are in good agreement with the experimental results and reveal that the oxygen addition to the metallic Ta phase, leads to a distortion of the Ta crystal structure, causing a decrease in density and an increase of the elastic constants.
\end{abstract}

\section{Introduction}

Tantalum (Ta) is a transition metal well known for its properties such as high density, mechanical resistance, biocompatibility and thermal stability [1,2]. However, its high cost and high density makes Ta inappropriate for use as bulk material [3]. On the other hand, tantalum oxides $\left(\mathrm{TaO}_{\mathrm{x}}\right)$ have great technological interest, especially due to their electrical and optical properties, such as high transparency, high refractive index $(\mathrm{n} \approx 2.2$ at $633 \mathrm{~nm})$ and high dielectric constant $\left(\varepsilon_{\mathrm{r}} \approx 25\right)$. Furthermore, $\mathrm{TaO}_{\mathrm{x}}$ coatings have been employed as ion conductors in electrochromic devices [4-7].

Bulk Ta has a body centered cubic (bcc) stable phase with high toughness and ductility, as well as, low electrical resistivity. However, Ta can also exhibit a harder and more brittle tetragonal metastable phase with higher electrical resistivity, which is usually obtained in thin films
[1]. Depending on the deposition conditions and the type of substrate, Ta coatings can show any of these two phases or a mixture of them [8].

$\mathrm{TaO}_{\mathrm{x}}$ coatings are known to exhibit a large range of chemical compositions. The most common $\mathrm{TaO}_{\mathrm{x}}$ coatings have been identified as: 1) $\mathrm{Ta}_{2} \mathrm{O}$ with a bcc crystal structure; 2 ) $\mathrm{TaO}$ with a face centered cubic (fcc) structure; and 3) $\mathrm{TaO}_{2}$ with a tetragonal structure [5]. When oxygen is add to the metallic bcc Ta phase, the phases have great similarities since they are formed by the distortion of the Ta base structure [8-10]. All these phases can be found in coatings deposited by reactive dc magnetron sputtering [11-13].

Among all the Ta oxide phases, $\mathrm{Ta}_{2} \mathrm{O}_{5}$ phase is the most thermodynamically stable phase. The allotropic transformation of $\mathrm{Ta}_{2} \mathrm{O}_{5}$ at $\approx 1360{ }^{\circ} \mathrm{C}$ is well documented [14], including oxygen rich or oxygen deficient phases, but the crystal structure formed at high or low temperatures is still a subject of controversy. The $\mathrm{Ta}_{2} \mathrm{O}_{5}$ crystal, as well as,

\footnotetext{
* Corresponding author at: Universidade do Minho, Escola de Ciências, Departamento de Física, Campus de Azurém, 4800-058 Guimarães, Portugal. E-mail address: alves.cristiana89@gmail.com (C.F.A. Alves).

URL: http://smf-materials.com/ (C.F.A. Alves).
} 
its electronic structure and oxygen vacancies have been studied for several years and many crystalline structures have been proposed [14,15]. K. Lehovec [16] proposed an orthorhombic phase with a large

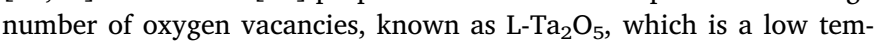
perature phase. At high temperatures, other authors $[17,18]$ proposed a tetragonal phase, known as $\mathrm{H}-\mathrm{Ta}_{2} \mathrm{O}_{5}$. Later, Stephenson and Roth [19] reported a vacancy-free $\mathrm{L}-\mathrm{Ta}_{2} \mathrm{O}_{5}$ orthorhombic structure as the lowtemperature crystal structure, commonly named as $\beta-\mathrm{Ta}_{2} \mathrm{O}_{5}$. Moreover, a hexagonal low-temperature metastable phase, $\delta-\mathrm{Ta}_{2} \mathrm{O}_{5}$, has been also identified [20]. All these $\mathrm{Ta}_{2} \mathrm{O}_{5}$ phases are similar with respect to the position of the oxygen ions along the $c$ direction. The main difference is the position of oxygen ions in the $a$ and $b$ directions [21].

Several thin film deposition techniques have been employed to deposit $\mathrm{Ta}$ and $\mathrm{TaO}_{\mathrm{x}}$ coatings. However, direct current (DC) magnetron sputtering is the most industrially used technique for the deposition of coatings as high deposition rates are obtained, making the process more cost effective [22].

Previously, the authors have deposited $\mathrm{Ta}_{1-\mathrm{x}} \mathrm{O}_{\mathrm{x}}$ coatings by magnetron sputtering [23-25]. Yet, we found that it was difficult to clearly distinguish the various crystal structures present in the deposited $\mathrm{Ta}_{1-\mathrm{x}} \mathrm{O}_{\mathrm{x}}$ coatings. So far, the experimental analysis has been more limited to structure identification. On the other hand, the correlation between crystal-structure and specific elastic properties supported by theoretical studies may be key for better understanding the evolution of the coatings. As result, this work proposes a theoretical and experimental approach, to understand the evolution of the structural and elastic properties of Ta-based coatings deposited by magnetron sputtering as a function of oxygen content. New Ab-initio density functional theory calculations were carried out for $\mathrm{Ta}_{\mathrm{x}} \mathrm{O}_{\mathrm{y}}$ structures, to obtain information about the theoretical lattice parameters, energy of formation and elastic properties as a function of oxygen addition to a pure $\mathrm{Ta}$ bcc lattice. Structure and chemical composition were investigated using advanced transmission electron microscopy.

\section{Experimental details}

\subsection{Deposition of coatings}

Ta-based coatings were deposited by reactive DC magnetron sputtering from a high-purity Ta target $(99.96 \%)\left(200 \times 100 \mathrm{~mm}^{2}\right)$ onto single crystalline silicon ( $\mathrm{Si})(100)\left(10 \times 10 \mathrm{~mm}^{2}\right)$. The substrates were ultrasonically cleaned using ultrasonic baths: first in distilled water; second in ethanol; and lastly in acetone; for $10 \mathrm{~min}$ in each solvent. This process removes dust, impurities and organics from the substrate surface, which subsequently enhances the coating adhesion. The adhesion was further improved by an in-situ argon (Ar) etching process, immediately before the deposition of the coatings, to remove the remaining impurities and surface oxides on the target and substrate surface. Additionally, a Ta interlayer of around $300 \mathrm{~nm}$ was deposited before the Ta-based functional layer to further enhance the adhesion of the ceramic coatings to the substrate.

In order to achieve a broad range of compositions in $\mathrm{TaO}_{\mathrm{x}}$ films, different current densities (different power densities) were used by adapting the reactive gases fluxes [23]. The depositions were carried out in an $\mathrm{Ar}+\mathrm{O}_{2}$ atmosphere with the substrates rotating at $70 \mathrm{~mm}$ away from the target at constant speed of $7 \mathrm{rpm}$. The deposition temperature and the bias voltage were kept constant at approximately $200{ }^{\circ} \mathrm{C}$ and $-75 \mathrm{~V}$, respectively. The current density applied to the Ta target $(\mathrm{J})$ was varied from 10 to $5 \mathrm{~mA} \cdot \mathrm{cm}^{-2}$ in order to achieve stoichiometric tantalum oxide $\left(\mathrm{Ta}_{2} \mathrm{O}_{5}\right)$. Ar flow was kept constant, while the $\mathrm{O}_{2}$ flow was adjusted to create a proper reactive atmosphere to produce $\mathrm{Ta}_{1-\mathrm{x}} \mathrm{O}_{\mathrm{x}}$ coatings, as depicted in Table 1 . The base pressure was $6 \times 10^{-4} \mathrm{~Pa}$ and the discharge pressure ranged from 0.6 to $0.7 \mathrm{~Pa}$ depending on the gas flow. The sample acronyms used in Table 1 represent the applied current density (C) and oxygen flow (F) used for each deposition.

\subsection{Physical, chemical, structural and elastic properties characterization}

The chemical composition of Ta-based coatings was determined by electron probe micro-analysis (EPMA), using a Cameca equipment: model Camebax SX50. Five measurements were performed randomly in each sample to statistically validate the measurements. The accelerating voltage of the electron beam was $10 \mathrm{kV}$ and the current was $40 \mathrm{nA}$. The experimental error of this technique is $<1$ at.\%. A LEICA S360 scanning electron microscope (SEM), operating at $10 \mathrm{kV}$ in secondary electron mode, was used to measure the coating's thickness, thus allowing the calculation of the deposition rate. The structure and phase distribution of the coatings were determined by $\mathrm{X}$-ray diffraction (XRD). XRD analysis was performed using a Bruker D8 Discover, operating at $40 \mathrm{kV}$ and $40 \mathrm{~mA}$, with $\mathrm{Cu}$ radiation $\left(\lambda k_{\alpha 1}=0.1540600 \mathrm{~nm}\right.$ and $\left.\lambda k_{\alpha 2}=0.1544339 \mathrm{~nm}\right)$, equipped with collimator. The experiments were carried out with a grazing angle geometry $\left(1^{\circ}\right)$. All the tests were performed with a step size of $0.025^{\circ}$ and a time per step of $2 \mathrm{~s}$, in $25-75^{\circ}$ range.

Cross-section samples were prepared using a Helios 450S (FEI) focus ion beam to perform TEM (transmission electron microscopy) and STEM/ EDS (scanning transmission electron microscopy/energy dispersive X-ray spectroscopy) analyses. High angle annular dark field (HAADF) STEM images were acquired using probe-corrected and double-corrected FEI Titan microscopes operated at 200 and $300 \mathrm{keV}$, respectively. The images were recorded using a convergence angle of $21 \mathrm{mrad}$ with a pixel dwell time set at $10 \mu \mathrm{s}$. Phase contrast (PC) and bright-field (BF) images were recorded using a double-corrected FEI Titan microscope operated at $300 \mathrm{keV}$. Energy dispersive X-ray spectroscopy mapping (EDS-mapping) was performed in the same instrument, which is equipped with a Super-X EDS detector. Iterative maps of $512 \times 512$ pixels were recorded with a dwell time per pixel of $10 \mu$ s at 200 and $300 \mathrm{keV}$, under a current between 200 and $400 \mathrm{pA}$ and collection times of $15 \mathrm{~min}$.

The Young's modulus of the films was measured by surface acoustic waves (SAW). Details of the technical setup and the mathematical procedure of this method are described elsewhere [26]. Short laser pulses (laser wavelength: $337 \mathrm{~nm}$, pulse length: $3 \mathrm{~ns}$, pulse energy: $80 \mu \mathrm{J}$ ) were used to generate acoustic impulses with a bandwidth up to about $200 \mathrm{MHz}$. The elastic surface vibrations are received by a piezo-electric sensor. The sensor signal is amplified and recorded by an oscilloscope. The laser beam is focused by a cylindrical lens into a line on the sample surface to generate a straight SAW front which propagates perpendicular to the direction of the laser line. The position of the laser line to the sensor is precisely varied by a translation stage (positioning error: $\Delta \mathrm{x}<1.5 \mu \mathrm{m}$ ) to detect acoustic signals for different distances between the laser-acoustic source and the sensor. The Fourier transformation of the signals enables their amplitude and phase spectra to be calculated. The phase spectra are used to calculate the dispersion curve of the surface acoustic wave - c (f), which $\mathrm{c}$ is the phase velocity and depends on the frequency (f). As the energy of the surface acoustic wave is concentrated at the material's surface, the dispersion curve is very sensitive to the properties of the film material such as Young's modulus, Poisson's ratio, density, and film thickness. Making use of a theoretical approach enables the dispersion curve to be calculated with assumed values for the elastic parameters and density of film and substrate, as well as, film thickness. The parameters of the test sample can be determined by fitting the theoretical curve to the experimental data, which was measured with the laser-acoustic method. The information content of the dispersion curve depends on the shape and bandwidth of the curve. Usually, the fit procedure cannot calculate all parameters involved. In the present case, a Poisson's ratio of 0.34 was taken from the literature [27] and the film thickness was determined by SEM and entered into the fitting curve. For the silicon substrate, the elastic parameters $\mathrm{C}_{11}=165.7 \mathrm{GPa}, \mathrm{C}_{12}=63.5 \mathrm{GPa}, \mathrm{C}_{44}=79.6 \mathrm{GPa}$ and the density $\rho=2.33 \mathrm{~g} / \mathrm{cm}^{3}$ were used. With this input data, Young's modulus and density of the $\mathrm{Ta}_{1-\mathrm{x}} \mathrm{O}_{\mathrm{x}}$ films were calculated. The results of the Young's modulus are the average of six SAW measurements of the elastic properties of $\mathrm{Ta}_{1-\mathrm{x}} \mathrm{O}_{\mathrm{x}}$ coatings, deposited onto Si substrates. The Poisson ratio (0.34) was kept constant in all measurements. 
Table 1

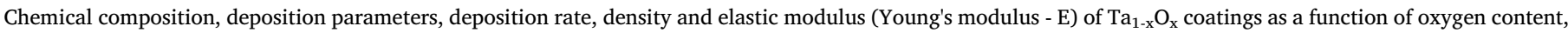

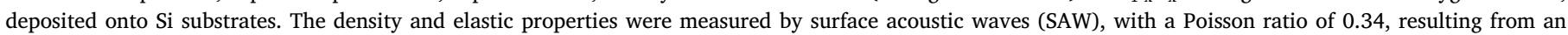
average of six measurements.

\begin{tabular}{|c|c|c|c|c|c|c|c|c|c|c|c|}
\hline \multirow[t]{2}{*}{ Sample } & \multirow[t]{2}{*}{ Acronym } & \multicolumn{2}{|c|}{$\begin{array}{l}\text { Chemical composition (at. } \\
\%)\end{array}$} & \multirow[t]{2}{*}{$\begin{array}{l}\mathrm{O}_{2} \text { Flow } \\
(\mathrm{sccm})\end{array}$} & \multirow{2}{*}{$\begin{array}{l}\mathrm{O}_{2} \text { partial } \\
\text { pressure } \\
\left(\times 10^{-2} \mathrm{~Pa}\right)\end{array}$} & \multirow{2}{*}{$\begin{array}{l}\text { Current } \\
\text { density } \\
\left(\mathrm{mA} / \mathrm{cm}^{2}\right)\end{array}$} & \multirow[t]{2}{*}{$\begin{array}{l}\text { Target } \\
\text { potential (V) }\end{array}$} & \multirow[t]{2}{*}{$\begin{array}{l}\text { Deposition } \\
\text { rate }(\mu \mathrm{m} / \mathrm{h})\end{array}$} & \multirow[t]{2}{*}{ Thickness $(\mu \mathrm{m})$} & \multicolumn{2}{|l|}{ SAW } \\
\hline & & $\mathrm{Ta}$ & $\mathrm{O}$ & & & & & & & Density $\left(\mathrm{g} / \mathrm{cm}^{3}\right)$ & $\begin{array}{l}\text { Elastic } \\
\text { modulus } \\
(\mathrm{GPa})\end{array}$ \\
\hline Ta1 & C10F0 & $95 \pm 0.3$ & $5 \pm 0.3$ & 0 & N/A & 10 & $425 \pm 20$ & 2.3 & 4.5 & $17.6 \pm 0.13$ & $196 \pm 6$ \\
\hline TO1 & $\mathrm{C} 10 \mathrm{~F} 2$ & $89 \pm 0.6$ & $11 \pm 0.6$ & 2 & 5.2 & & $352 \pm 25$ & 2.1 & 4.2 & $16.2 \pm 0.09$ & $241 \pm 8$ \\
\hline TO3 & C10F6 & $73 \pm 0.2$ & $27 \pm 0.2$ & 6 & 10 & & $366 \pm 3.1$ & 2.3 & 4.5 & $15.7 \pm 0.09$ & $248 \pm 7$ \\
\hline TO5 & C10F10 & $57 \pm 0.2$ & $43 \pm 0.2$ & 10 & 15 & & $419 \pm 3.3$ & 2.8 & 5.1 & $14.2 \pm 0.06$ & $239 \pm 6$ \\
\hline TO6 & C5F13 & $30 \pm 0.4$ & $70 \pm 0.4$ & 13 & 20 & 5 & $548 \pm 8.4$ & 1.9 & 3.8 & $8.96 \pm 0.09$ & $155 \pm 5$ \\
\hline
\end{tabular}

\section{Density functional theory calculations}

The structural and mechanical calculations reported herein were based on density functional theory (DFT) calculations employing the generalized gradient approximation (GGA) parametrized by Perdew, Burke, and Ernzerhof (PBE) [28] and the projector-augmented-wave method, as implemented in VASP code [29]. The core electrons were frozen within the Projector Augmented Wave (PAW) method [30,31], whereas valence electrons $\left(\mathrm{Ta}: 5 \mathrm{p}_{6} 5 \mathrm{~d}_{3} 6 \mathrm{~s}_{2} ; \mathrm{O}: 2 \mathrm{~s}_{2} 2 \mathrm{p}_{4}\right.$ ) were treated explicitly by a plane wave basis set with a cutoff energy of $520 \mathrm{eV}$ for structural optimizations and $700 \mathrm{eV}$ for elastic constants calculations. Brillouin-zone integration was performed on a Monkhorst-Pack [32] $k$ mesh of $20 \times 20 \times 20$ in the Methfessel-Paxton scheme [33] for Ta, $\mathrm{TaO}, \mathrm{Ta}_{2} \mathrm{O}, \mathrm{Ta}_{4} \mathrm{O}$ crystal structures with a smearing width of $0.2 \mathrm{eV}$ for the Fermi-surface broadening. In the case of $\mathrm{TaO}_{2},(\beta, \delta)-\mathrm{Ta}_{2} \mathrm{O}_{5}$ structures, the tetrahedron method with Blochl corrections was used with a k-mesh of $2 \times 4 \times 2$ for $\delta-\mathrm{Ta}_{2} \mathrm{O}_{5}$ and $12 \times 12 \times 14$ for the other structures [34]. The total energies were converged to better than $1 \mathrm{meV}$. The equilibrium lattice constants for different $\mathrm{Ta}_{2} \mathrm{O}_{5}$ structures were obtained through total energy minimization. The force tolerance for geometry relaxation was $0.01 \mathrm{eV} / \AA$.

The material density, formation enthalpy, and elastic properties of $\alpha$-Ta (Cubic, Im-3 m, ICCD card n. 00-004-0788), $\beta$-Ta (Tetragonal, P42/mnm, ICCD card n. 00-025-1280), $\mathrm{Ta}_{2} \mathrm{O}$ (Cubic, I-43 m, ICCD card n. 01-074-2305), $\mathrm{Ta}_{4} \mathrm{O}$ (Tetragonal, P4/mmm, ICCD card n. 03-0656450), TaO (Cubic, Fm-3 m, ICSD card n. 76,023), $\mathrm{TaO}_{2}$ (Tetragonal, $\mathrm{P} 42 / \mathrm{mnm}$, ICCD card n. 01-019-1297), $\beta-\mathrm{Ta}_{2} \mathrm{O}_{5}$ (Orthorhombic, Pccm, ICSD card n. 95,462) and $\delta-\mathrm{Ta}_{2} \mathrm{O}_{5}$ (Hexagonal, $\mathrm{P} 6 / \mathrm{mmm}$, reported in [35]) phases were calculated to study the evolution of the structural and elastic properties of the system with increased oxygen content. The formation enthalpy was calculated by

$E_{f}=E_{T a O_{x}}-E_{T a}-\left(\frac{x}{2}\right) \cdot E_{O_{2}}$

where $\mathbf{E}_{\mathbf{T a}}, \mathbf{E}_{\mathbf{O} 2}$ and $\mathbf{E}_{\mathbf{T a O x}}$ are the total energies of bcc Ta, molecular $\mathrm{O}_{2}$ and $\mathrm{TaO}_{\mathrm{x}}$ crystal structures, respectively. In this calculation, the correction to $\mathrm{O}_{2}$ total energy proposed by Wang was added [36].

The calculation of elastic moduli (the bulk and shear modulus) was done using the Voigt [37] and Reuss [38] averaging procedures which are expressed in terms of the stiffness constants, cij (Table 2), and compliances sij, respectively. In particular, the bulk and shear modulus in the Voigt approach are:

$B_{V}=\frac{1}{9}\left[\left(c_{11}+c_{22}+c_{33}\right)+2\left(c_{12}+c_{13}+c_{23}\right)\right]$

$G_{V}=\frac{1}{15}\left[\left(c_{11}+c_{22}+c_{33}\right)-\left(c_{12}+c_{13}+c_{23}\right)+3\left(c_{44}+c_{55}+c_{66}\right)\right]$

The corresponding expressions for the Reuss averaging are:

$B_{R}=\left[\left(s_{11}+s_{22}+s_{33}\right)+2\left(s_{12}+s_{13}+s_{23}\right)\right]^{-1}$
$G_{R}=15\left[4\left(s_{11}+s_{22}+s_{33}\right)-\left(s_{12}+s_{13}+s_{23}\right)+3\left(s_{44}+s_{55}+s_{66}\right)\right]^{-1}$

The elastic modulus (Young's modulus), E, and Poisson ratio, $\nu$, were obtained using the average values of Voigt and Reuss values, expressed as:

$E=\frac{9 B G}{3 B+G}$

$v=\frac{3 B-2 G}{2(3 B+G)}$

It is also important to calculate the elastic modulus for structures exhibiting a high degree of crystal anisotropy, as follows [39]:

$$
\begin{aligned}
E^{-1}= & s_{11} l_{1}^{4}+s_{22} l_{2}^{4}+s_{33} l_{3}^{4}+\left(2 s_{12}+s_{66}\right) l_{1}^{2} l_{2}^{2}+\left(2 s_{23}+s_{44}\right) l_{2}^{2} l_{3}^{2} \\
& +\left(2 s_{13}+s_{55}\right) l_{1}^{2} l_{3}^{2}
\end{aligned}
$$

where $\mathbf{l}_{1}, \mathbf{l}_{\mathbf{2}}, \mathbf{l}_{\mathbf{3}}$ are the direction cosines.

Additionally, SIMTRA [40] simulations were performed to estimate the mean energy deposited per incoming Ta particle. This code simulates the collisional transport of particles in the gas phase based on Monte-Carlo calculations of the mean free path distributions using a screened Coulomb potential for describing the Ta-Ar interaction and considering the chamber geometry. The nascent energy and angular distribution of the sputtered and backscattered neutral particles leaving the target for SIMTRA simulations are obtained using the SRIM code [41] assuming an incident energy of impinging Ar ions equal to $300 \mathrm{eV}$ corresponding to $75 \%$ of the discharge voltage. For the deposition conditions used $(p=0.6 \mathrm{~Pa}, T=473 \mathrm{~K}$, target-substrate distance of $7 \mathrm{~cm}$, substrate bias voltage of $-75 \mathrm{~V}$ ) a mean energy deposited of $70 \mathrm{eV} /$ atom was obtained and a Ta sputtering yield of 0.425 , which compares well with similar calculations [42].

\section{Results}

\subsection{Chemical and structural characterization of the coatings}

Various conditions such as current density and reactive gas parameters were selected in order to produce coatings with different properties. A complete analysis (hysteresis curves) of the deposition was performed, which can be found in a previous publication [23]. The chemical composition evolution as a function of $\mathrm{O}_{2}$ flow rate and applied current density are summarized in Table 1 . A progressive increase of the oxygen content is observed from 5 to 70 at.\% along with a decrease in Ta content from 95 down to 30 at.\%. The oxygen in the nonreactive Ta coating $(\mathrm{C} 10 \mathrm{~F} 0)$ could be attributed to residual $\mathrm{O}_{2}$ present in the deposition chamber, which arose from the water vapor adsorbed into the chamber walls.

The XRD patterns shown in Fig. 1a reveal a bcc phase for the nonreactive deposited film (C10F0 coating), corresponding to the stable $\alpha$ Ta. The formation of bcc $\alpha$-Ta phase in the C10F0 coating can be explained by the high substrate temperature during deposition. Recently, 
Table 2

Elastic constants of $\mathrm{Ta}$ and $\mathrm{TaO}_{\mathrm{x}}$ crystal structures, calculated by DFT, and reference values reported in the literature (NA means not applicable).

\begin{tabular}{|c|c|c|c|c|c|c|c|c|c|c|}
\hline Structure & $\Delta \mathrm{Hf}(\mathrm{kJ} / \mathrm{mol})$ & $\mathrm{C}_{11}(\mathrm{GPa})$ & $\mathrm{C}_{12}(\mathrm{GPa})$ & $\mathrm{C}_{13}(\mathrm{GPa})$ & $\mathrm{C}_{22}(\mathrm{GPa})$ & $\mathrm{C}_{33}(\mathrm{GPa})$ & $\mathrm{C}_{44}(\mathrm{GPa})$ & $\mathrm{C}_{66}(\mathrm{GPa})$ & $\mathrm{C}_{55}(\mathrm{GPa})$ & $\mathrm{C}_{23}(\mathrm{GPa})$ \\
\hline$\alpha-\mathrm{Ta}$ & 0.00 & 281 & 166 & 166 & 281 & 281 & 73 & 73 & 73 & 166 \\
\hline$\beta$-Ta & 0.01 & 302 & 146 & 159 & 302 & 290 & 67 & 49 & 49 & 159 \\
\hline $\mathrm{Ta}_{4} \mathrm{O}$ & -353 & 314 & 157 & 173 & 314 & 413 & 112 & 47 & 47 & 173 \\
\hline $\mathrm{Ta}_{2} \mathrm{O}$ & 72 & 32 & 185 & 185 & 32 & 32 & 38 & 38 & 38 & 185 \\
\hline$\alpha-\mathrm{Ta}+5$ at. $\%$ O interstitial & -5.14 & 288 & 166 & 166 & 288 & 288 & 73 & 73 & 73 & 166 \\
\hline $\mathrm{TaO}$ & -244 & 275 & 239 & 239 & 275 & 275 & -90 & -90 & -90 & 239 \\
\hline $\begin{array}{l}\mathrm{TaO}_{2} \\
\beta-\mathrm{Ta}_{2} \mathrm{O}_{5}\end{array}$ & -885 & 366 & 262 & 189 & 366 & 391 & 262 & 104 & 104 & 189 \\
\hline Our results & -1019 & 285 & 123 & 29 & 640 & 757 & 36 & 45 & 78 & 56 \\
\hline Wu, Y.-N., L. Li et al. [15] & NA & 290 & 126 & 52 & 263 & 428 & 78 & 52 & 39 & 115 \\
\hline \multicolumn{11}{|l|}{$\delta-\mathrm{Ta}_{2} \mathrm{O}_{5}$} \\
\hline Our results & -1117 & 242 & 90 & 154 & 226 & 582 & 59 & 65 & 63 & 154 \\
\hline Wu, Y.-N., L. Li et al. [15] & NA & 175 & 104 & 169 & 167 & 403 & 47 & 57 & 46 & 3 \\
\hline
\end{tabular}

a)

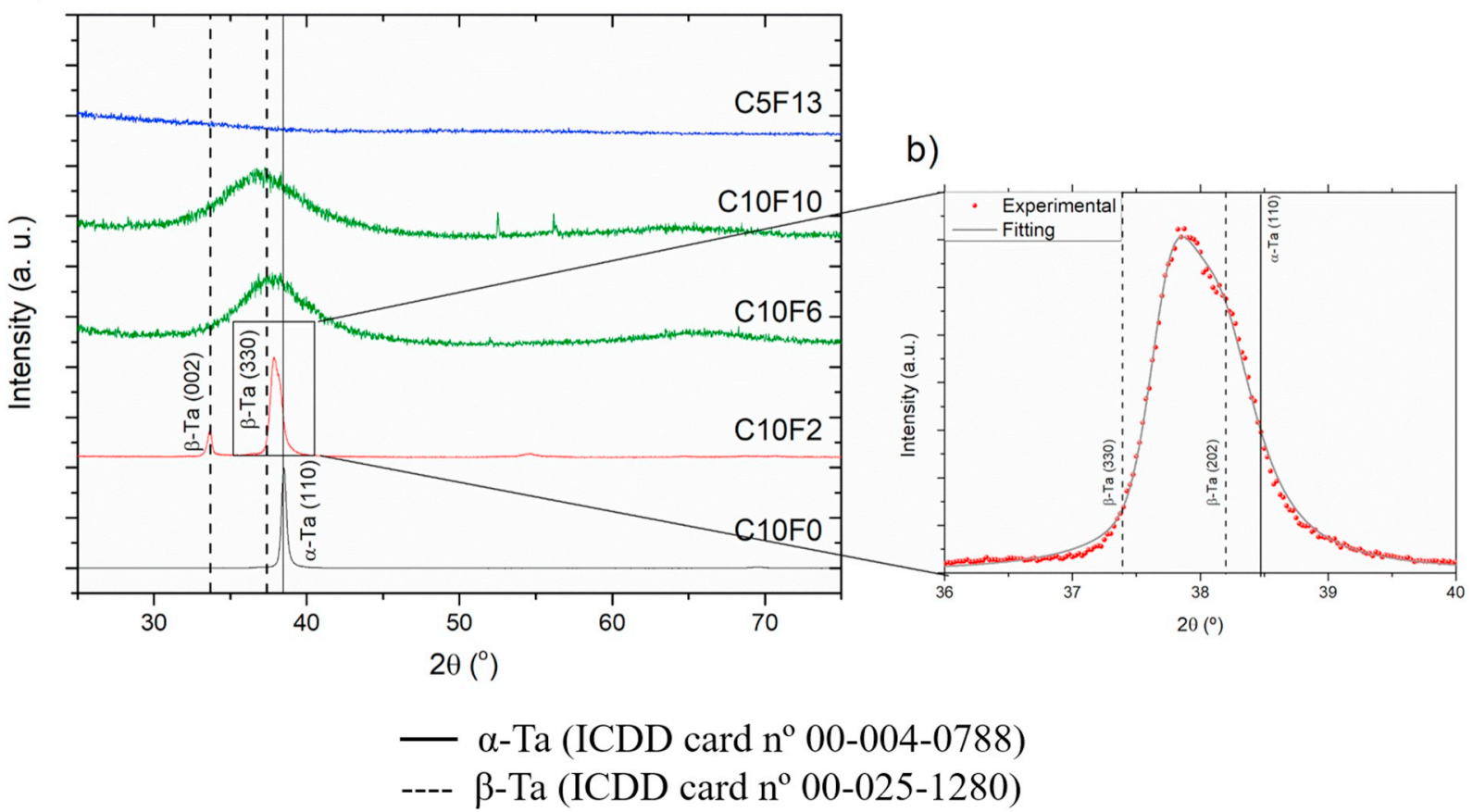

Fig. 1. Grazing incidence XRD patterns of the coatings deposited onto Si substrates as a function of the oxygen content.

it was demonstrated that the critical deposition temperature for the nucleation of $\alpha$-Ta phase on amorphous silicon is $600 \mathrm{~K}$ [42]. In this study, based on calculations using the SIMTRA simulations and SRIM code, a substrate temperature increase of $\sim 150-200 \mathrm{~K}$ (steel substrate, thickness $=2 \mathrm{~mm}$ ) can be estimated [43], leading to a final temperature of $620 \mathrm{~K}$, which is well above the critical temperature for $\alpha$-Ta nucleation. When the oxygen content increased slightly above 11 at.\% (C10F2) a diffraction peak nearby $33^{\circ}$ appears, corresponding to the $\beta$ Ta (002) phase. Also, the diffraction peak at $\approx 38^{\circ}$ becomes asymmetric (Fig. 1b) demonstrating that the material changed to a mixture of phases making difficult to identify their structure.

To better understand this issue, an electron diffraction pattern was obtained (Fig. 2a). Diffraction ring indexation was tried by comparing the experimental ring diameters with the theoretical values of the $\alpha$-Ta and $\beta$-Ta phases. In particular, the peaks in the intensity profile shown in the inset of Fig. 2a were first determined and then, the reciprocal distances were converted to real distances (Fig. 2b) in order to estimate the experimental interplanar spacing. In Fig. 2c, the ratio of the interplanar distances for the experimental, as well as, for theoretical $\alpha$-Ta and $\beta$-Ta phases is shown. All ratios were calculated with respect to the interplanar spacing associated with the first and more intense diffraction ring as the basis (e.g. $\mathrm{d} 2 / \mathrm{d} 1$; $\mathrm{d} 3 / \mathrm{d} 1$, etc....). As shown in Fig. $2 c$ and considering the error bars, it is not possible to determine whether we have a mixture of the $\alpha$-Ta and $\beta$-Ta phases, or a single $\alpha$ Ta or $\beta$-Ta phase.

Moreover, it was reported elsewhere [25] that coatings with intermediate oxygen contents (C10F6 and C10F10) became nanocrystalline. To further investigate this issue, we have performed electron diffraction. Fig. 3 a reveals the presence of continuous diffraction rings. For the case of an amorphous material, a more diffuse electron diffraction pattern is expected. To better understand this result, the reciprocal distances were first determined by the intensity profile across the various rings (inset of Fig. 3a), as well as, the corresponding real distances (Fig. 3b). Subsequently, these calculated distances were compared with the radial distribution function for both $\alpha$-Ta and $\beta$-Ta phases (see supplementary Fig. 1), which would represent the interatomic distances between Ta and Ta in an amorphous material with short range order. As these do not match, this seems to infer the existence of nanocrystals, although, as shown above, the distinction between $\alpha$-Ta and $\beta$-Ta phases is difficult to determine. This possibility was further investigated using phase contrast imaging (Fig. 3c), but the presence of nanocrystals is difficult to observe. This is most likely due to the overlap of many of 

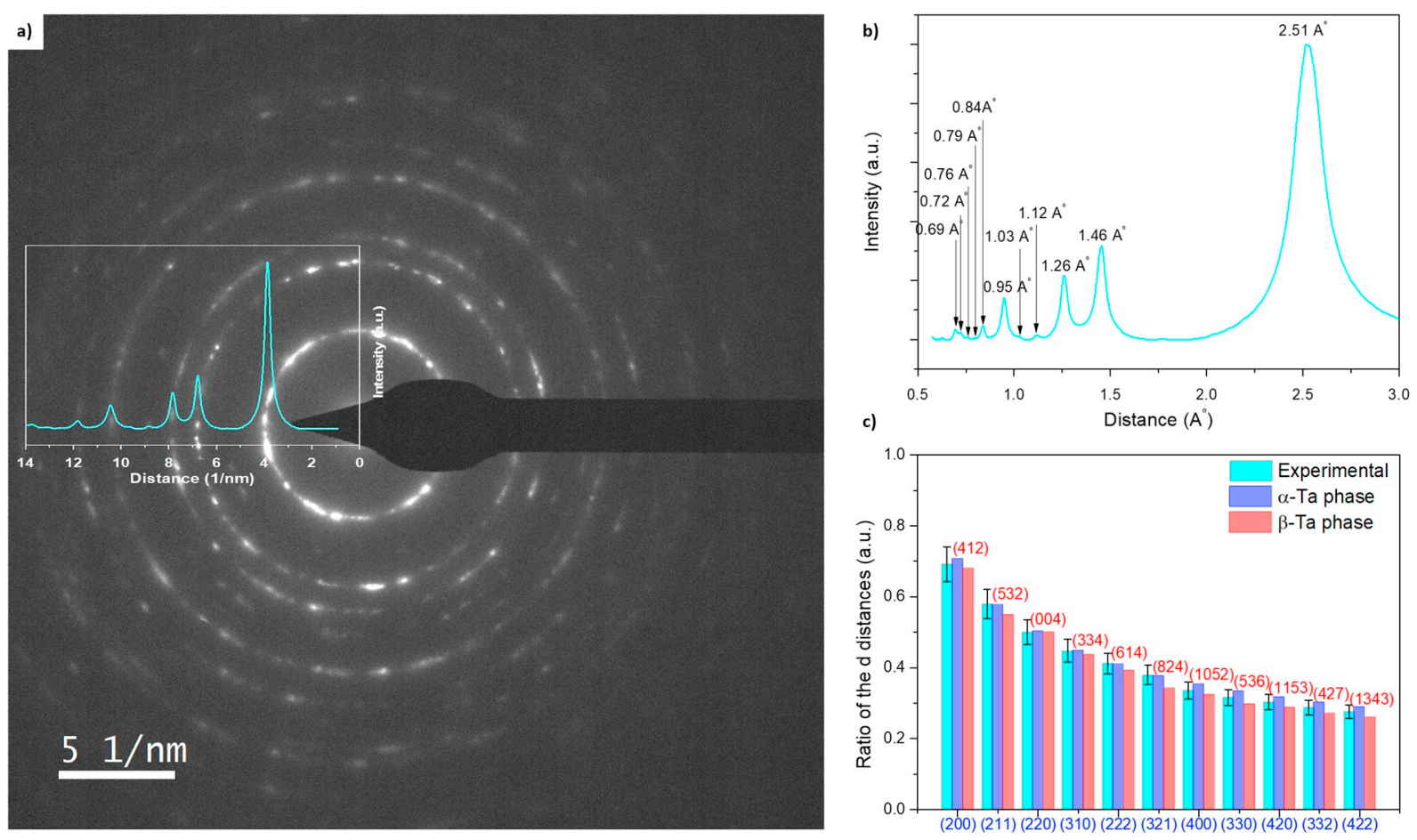

Fig. 2. a) Electron diffraction pattern of $\mathrm{C} 10 \mathrm{~F} 2$ coating; b) Interplanar spacings associated with the diffraction rings shown in a); and c) Possible indexation for the two Ta phase crystal structures. All ratios were calculated with respect to the interplanar spacing associated with the first and more intense diffraction ring as the basis (e.g. d2/d1; d3/d1, etc....).

these nanocrystals across the entire thickness $(60-80 \mathrm{~nm})$ and possibly the presence of amorphous material as well.

In addition, when the oxygen content is increased a shift of the peak to the left is observed, which reveals an increase in the interplanar distance and corroborates the presence of nanocrystals. The shift in the $\mathrm{X}$-ray peak can be due to: (i) changes in chemical composition and/or, (ii) an increase of the compressive residual stresses. Following the previous deposition of oxide coatings by magnetron sputtering without substrate bias, no significant changes in residual stresses have occurred when the chemical composition is changed. Therefore, the observed shift of the X-ray diffraction peaks may be attributed to an increase of the inter-atomic distance induced by the presence of oxygen.

Furthermore, the coating with the highest oxygen content (C5F13) proved to be amorphous, without the presence of any diffraction peak.

\subsection{Elastic modulus analysis}

The density and elastic modulus (Young's modulus - E), determined by SAW measurements, are shown in Table 1, as a function of the oxygen content. In the calculation of elastic modulus, the film thickness (evaluated by SEM) and the Poisson ratio of 0.34 were used for fitting.

Generally, with the incorporation of oxygen in metallic Ta, the

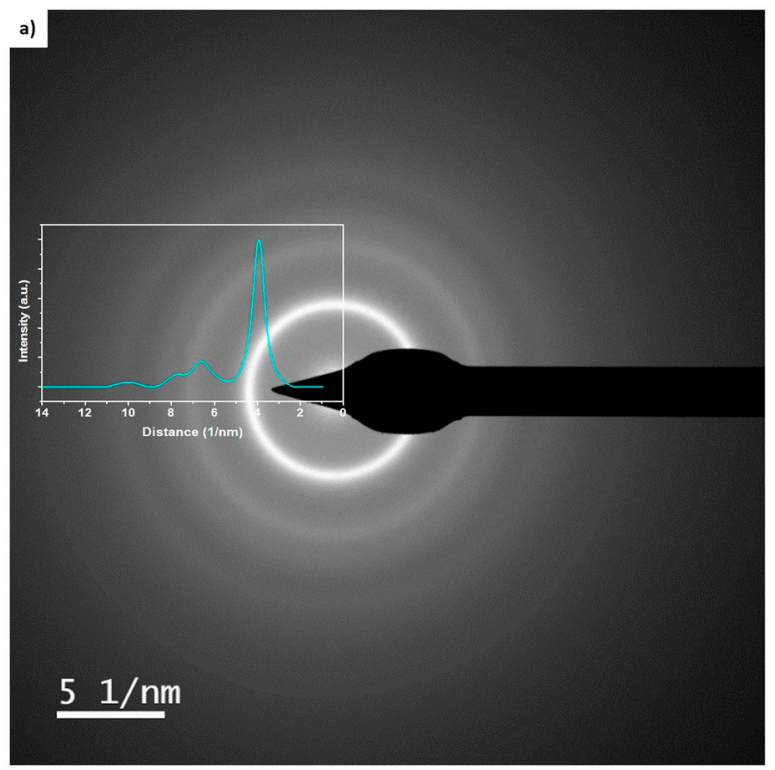

b)
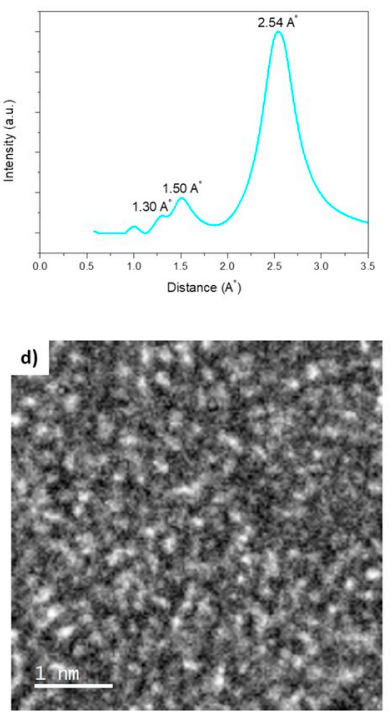
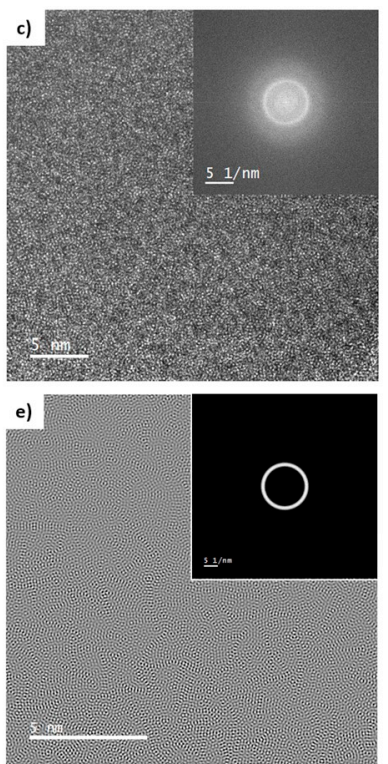

Fig. 3. a) Electron diffraction pattern of C10F6 coating; b) Intensity profile of the diffraction rings converted into real space; c) Cross section phase contrast TEM image; d) Higher magnification of the image shown in c); and e) Inverted Fast Fourier Transform (FFT) using the first diffraction ring shown in FFT of image c). 
Table 3

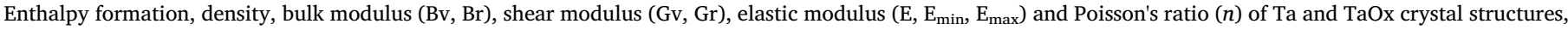
estimated by DFT calculations.

\begin{tabular}{|c|c|c|c|c|c|c|c|c|c|}
\hline Structure & Density $\left(\mathrm{g} / \mathrm{cm}^{3}\right)$ & $\mathrm{Bv}(\mathrm{GPa})$ & $\mathrm{Gv}(\mathrm{GPa})$ & $\mathrm{Br}(\mathrm{GPa})$ & $\mathrm{Gr}(\mathrm{GPa})$ & $\mathrm{E}(\mathrm{GPa})$ & $\mathrm{E}_{\min }(\mathrm{GPa})$ & $\mathrm{E}_{\max }(\mathrm{GPa})$ & $n$ \\
\hline$\alpha$-Ta & 16.59 & 205 & 66 & 205 & 66 & 179 & 157 & 195 & 0.35 \\
\hline$\beta-\mathrm{Ta}$ & 16.26 & 202 & 62 & 202 & 59 & 165 & 143 & 199 & 0.36 \\
\hline $\mathrm{Ta}_{4} \mathrm{O}$ & 15.64 & 227 & 77 & 222 & 67 & 196 & 146 & 290 & 0.35 \\
\hline$\alpha$-Ta +5 at. $\%$ O interstitial & 16.33 & 207 & 68 & 207 & 68 & 184 & 166 & 196 & 0.35 \\
\hline $\mathrm{TaO}_{2}$ & 9.11 & 267 & 126 & 266 & 97 & 293 & 168 & 380 & 0.32 \\
\hline$\beta-\mathrm{Ta}_{2} \mathrm{O}_{5}$ & 7.13 & 233 & 130 & 199 & 68 & 257 & 127 & 751 & 0.30 \\
\hline$\delta-\mathrm{Ta}_{2} \mathrm{O}_{5}$ & 7.44 & 205 & 81 & 161 & 71 & 200 & 161 & 434 & 0.32 \\
\hline
\end{tabular}

density decrease, due to the distortion of the Ta structure, while the elastic modulus increases, due to the formation of stronger ionic/ covalent $\mathrm{Me}-\mathrm{O}$ bonding. With further oxygen incorporation, the elastic modulus is enhanced due to the increase of stronger chemical bonds. Yet, the C5F13 coating does not follow the same tendency, as an unexpected decrease in the elastic modulus is observed.

Ab-initio DFT calculations were performed to obtain the enthalpy of formation, density, Poisson ratio and elastic modulus (average, max and min values depending on crystalline orientation) for different Ta and $\mathrm{TaO}_{\mathrm{x}}$ phases in order to understand this behavior. The results are shown in Table 2 and Table 3. The calculations predict an increase of phase stability with the addition of oxygen. It is important to note that $\mathrm{Ta}_{2} \mathrm{O}$ and $\mathrm{TaO}$ were found to be thermodynamically unstable structures under stress. The former presents a large enthalpy of formation $\left(\Delta \mathrm{H}_{\mathrm{f}}>0\right)$ and born instability $\left(\mathrm{C}_{11}-\mathrm{C}_{12}<0\right)$, while the latter shows shear elastic instability $\left(\mathrm{C}_{44}<0\right)$ (see Table 2). Thus, considering that coatings obtained by magnetron sputtering are normally in a stress state, these phases are not considered for further analysis. Moreover, the $\mathrm{Ta}_{4} \mathrm{O}$ structure shows remarkable stability and may be seen as a bcc Ta with oxygen atoms in interstitial positions.

As final remark, it is important to note that the DFT estimated values for the lattice parameter and density are in good agreement with the values reported in the ICDD/ICSD database (see Table 4).

The density obtained by DFT calculations is also in a good agreement with both SAW experimental data and literature results. With the increasing addition of oxygen to the Ta phase, a decrease in the density of the crystal structures is observed, explained by the incorporation of oxygen atoms into the Ta leading to a distortion of the initial crystal structure [8]. In what concerns the elastic modulus (Young's modulus) of pure Ta phase, the experimental results and DFT calculations are in good agreement. In the case of $\mathrm{Ta}_{1-\mathrm{x}} \mathrm{O}_{\mathrm{x}}$ coatings, the evolution of the elastic modulus must be carefully analyzed. In fact, there is a significant increase of elastic modulus from the non-reactive C10F0 coating to the C10F2 coating, despite the small difference in oxygen content. Moreover, the value of the elastic modulus measured for the sample with mixture of phases (C10F2) is much larger than the values achieved by DFT calculations for Ta metallic phases ( $\alpha$ and $\beta$ ). On this basis, theoretical simulations were performed for the $\alpha$-Ta base lattice with the interstitial addition of different amounts of oxygen. Naturally, depending on the oxygen content added, the base crystalline structure evolves to other structures. For instance, $\alpha$-Ta +5 at. $\% \mathrm{O}$ maintains the bcc phase, while $\mathrm{Ta}_{4} \mathrm{O}(\alpha$-Ta +20 at.\% O) assumes the very stable tetragonal phase $(\Delta \mathrm{H}<0)$. Yet, the $\mathrm{E}$ values achieved by $D F T$ calculations remain smaller than the elastic modulus measured for the C10F2 sample. To further analyze this sample, HAADF STEM, bright-field (BF) TEM and phase contrast (PC) TEM images of the cross section were acquired. STEM-EDS mapping (Fig. 4a) shows an oxygen accumulation at the column boundaries, which might be due to surface passivation or oxygen segregation. Additionally, in both BF and PC TEM images (Fig. 4b and c), the presence of an amorphous oxide phase at the column boundaries in confirmed, which may act as a second phase, leading to an increase of the elastic modulus. Planar view HAADF STEM, BF TEM and PC TEM images were also acquired and revealed the same results (see Supplementary Fig. 2).

In the case of coatings with intermediate oxygen content, C10F6 and C10F10), an increase of the oxygen leads to both a loss of crystallinity and a decrease of the density. To further analyze the structure, STEM images of the cross section were acquired. HAADF-STEM images (Fig. 5) show changes in contrast along the film thickness, indicating a multilayered growth for both $\mathrm{C} 10 \mathrm{~F} 6$ and $\mathrm{C} 10 \mathrm{~F} 10$ coatings, which makes a direct comparison between the DFT and the experimental results inappropriate. Such multilayered growth is characterized by changes in

Table 4

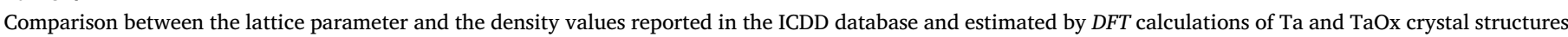
(NA means not applicable).

\begin{tabular}{|c|c|c|c|c|c|}
\hline \multirow[t]{2}{*}{ Structure } & \multicolumn{3}{|l|}{ Database } & \multicolumn{2}{|l|}{ DFT calculations } \\
\hline & Lattice parameter $(\AA)$ & Density & Card n. ${ }^{\circ}$ & Lattice parameter $(\AA)$ & Density $\left(\mathrm{g} / \mathrm{cm}^{3}\right)$ \\
\hline$\alpha-\mathrm{Ta}$ & $\mathrm{a}=3.31$ & 16.63 & ICDD 00-004-0788 & $\mathrm{a}=3.31$ & 16.59 \\
\hline \multirow[t]{2}{*}{$\beta-\mathrm{Ta}$} & $a=10.19$ & 16.33 & ICDD 00-025-1280 & $\mathrm{a}=10.21$ & 16.26 \\
\hline & $c=5.31$ & & & $c=5.32$ & \\
\hline \multirow[t]{3}{*}{$\mathrm{Ta}_{4} \mathrm{O}$} & $\mathrm{a}=7.19$ & 16.32 & ICDD 03-065-6450 & $\mathrm{a}=7.39$ & 15.64 \\
\hline & $\mathrm{b}=3.27$ & & & $\mathrm{~b}=3.24$ & \\
\hline & $\mathrm{c}=3.20$ & & & $c=3.24$ & \\
\hline $\mathrm{Ta}_{2} \mathrm{O}$ & $a=6.68$ & 16.84 & ICDD 01-074-2305 & $\mathrm{a}=7.51$ & 11.62 \\
\hline$\alpha$-Ta +5 at. $\% O$ interstitial & NA & NA & NA & NA & 16.33 \\
\hline $\mathrm{TaO}$ & 4.43 & 15.04 & ICSD 76023 & $\mathrm{a}=4.50$ & 13.81 \\
\hline \multirow[t]{2}{*}{$\mathrm{TaO}_{2}$} & $\mathrm{a}=4.75$ & 8.89 & ICDD 00-037-0117 & $\mathrm{a}=4.99$ & 9.11 \\
\hline & $c=3.09$ & & & $c=2.88$ & \\
\hline \multirow[t]{3}{*}{$\beta-\mathrm{Ta}_{2} \mathrm{O}_{5}$} & $\mathrm{a}=6.22$ & 8.24 & ICSD 95462 & $a=6.52$ & 7.13 \\
\hline & $\mathrm{b}=3.68$ & & & $\mathrm{~b}=3.69$ & \\
\hline & $c=7.79$ & & & $c=7.78$ & \\
\hline \multirow[t]{3}{*}{$\delta-\mathrm{Ta}_{2} \mathrm{O}_{5}$} & $\mathrm{a}=14.50$ & NA & Ref [34] & $\mathrm{a}=14.75$ & 7.44 \\
\hline & $c=7.76$ & & & $\mathrm{~b}=14.87$ & \\
\hline & & & & $c=7.75$ & \\
\hline
\end{tabular}



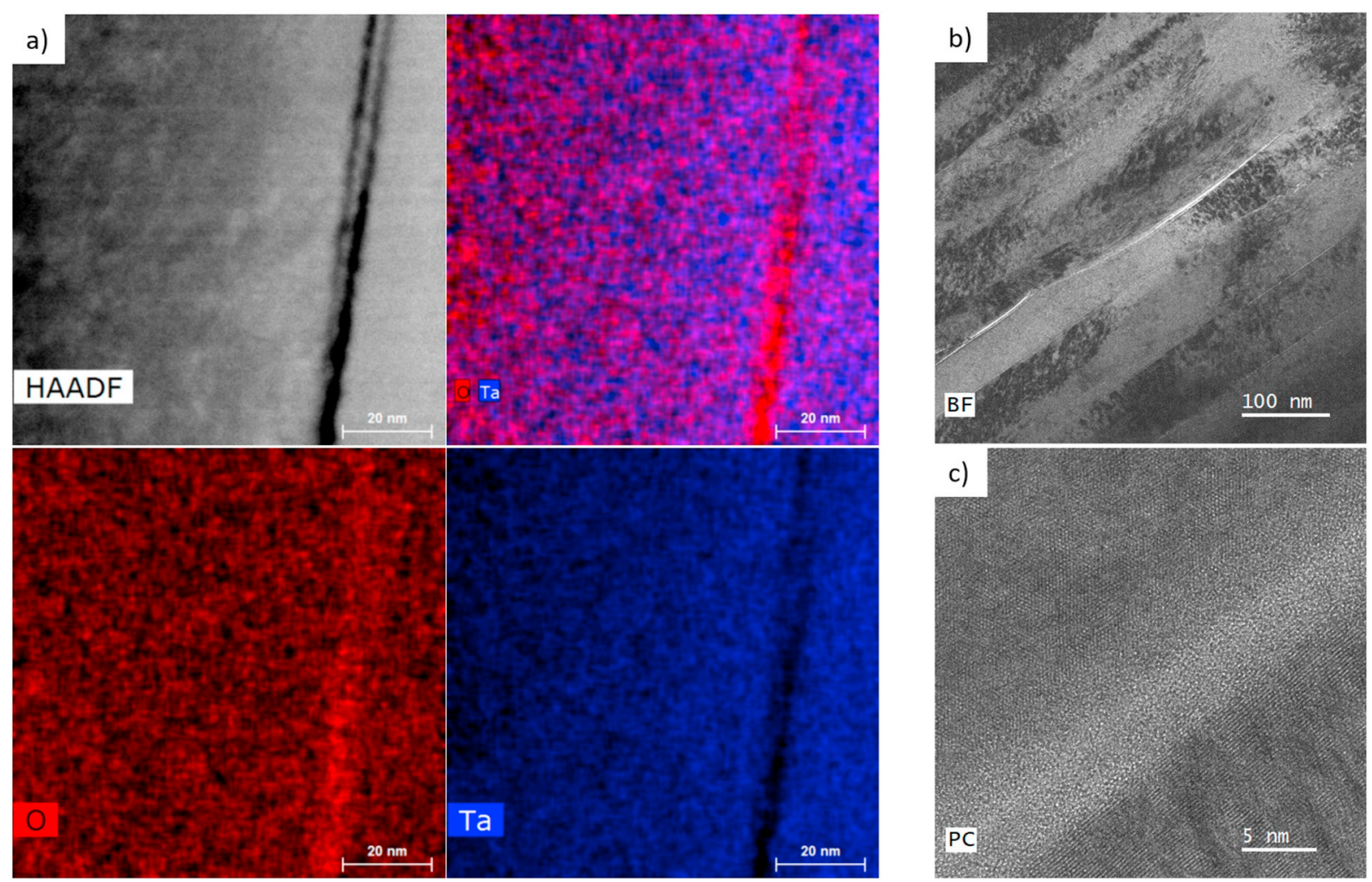

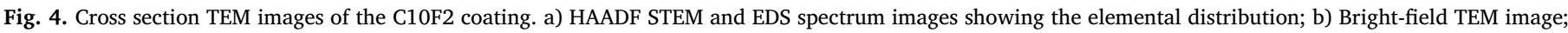
and c) Phase contrast TEM image.
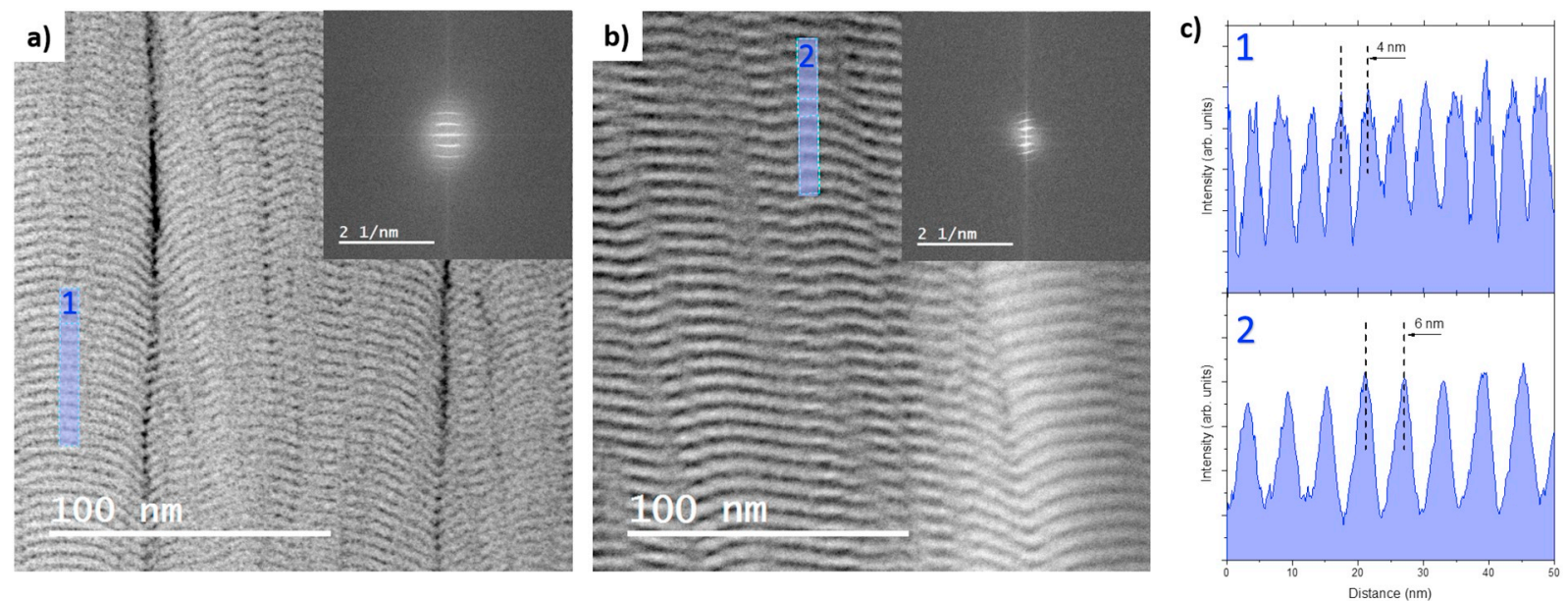

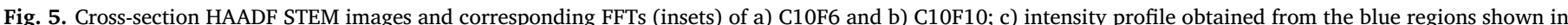

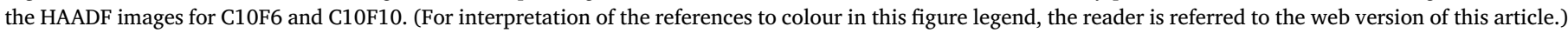

density, revealed by the variation of contrast in the image. In order to better understand the composition of each layer, STEM-EDS mapping was carried out, as shown in Fig. 6. Clearly, a modulation of the Ta content is observed as a function of the film thickness (traced by the green arrow), as shown in Fig. 6b, where the brighter regions represent the tantalum-rich zones, while the darker zones show depletion of tantalum.

This multilayer configuration is attributed to the deposition conditions. In fact, the depositions were carried out using only one Ta target in a non-poisoned mode (transition zone) and rotation of the substrate holder [23]. Therefore, the formation of a differentiated plasma surrounding the substrate holder can be expected. When the sample is facing the target, a fresh metallic Ta layer is deposited, which is very difficult to oxidize due to the high Ta deposition rate as a consequence of the high Ta sputtering yield. On the other hand, when the sample is turning around, the oxidative plasma environment $\left(\mathrm{Ar}+\mathrm{O}_{2}\right)$ promotes the oxidation of the films, which results in an increase of oxygen in the surface of the Ta layer (see Fig. 5). This behavior was also found in other similar systems such as $\mathrm{Ti}-\mathrm{Al}-\mathrm{O}-\mathrm{N}$ [44].

The multilayer growth, where the elastic modulus is dominated by the law of mixtures, combined with the overall decrease in crystallinity of the coatings with increasing oxygen content, explain the high elastic modulus values.

Finally, despite of the fact that C5F13 exhibits a higher oxygen content, it reveals the lowest elastic modulus and density values, $155 \mathrm{GPa}$ and $9 \mathrm{~g} / \mathrm{cm}^{3}$, respectively. This density level is attained by the large incorporation of oxygen in the structure. Moreover, according to previous results [23], C5F13 coating is formed by a narrow columnar 

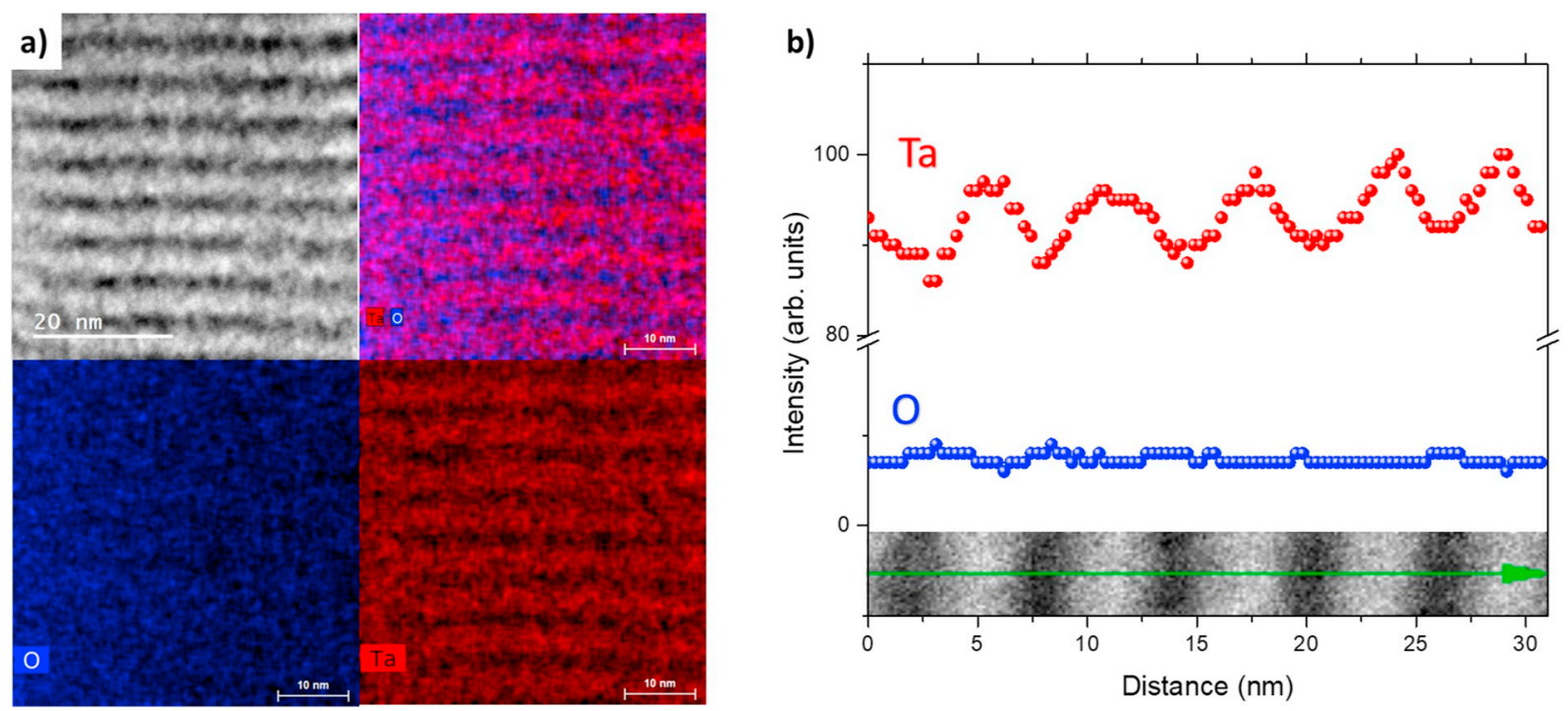

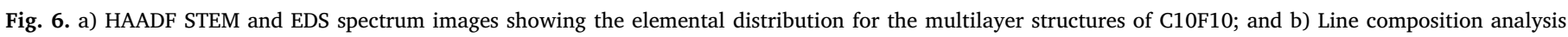
acquired by EDS for 5 bilayers of C10F10 sample.

morphology, caused by the lower applied current density, thus exhibiting lower density than C10F6 and C10F10 coatings which revealed a featureless morphology. These factors help to explain the decrease of the elastic the modulus for the C5F13 coating.

Fig. 7 show an overview of the density (Fig. 7a) and elastic modulus (Fig. 7b) evolution as a function of oxygen content for the experimental SAW for the deposited samples and DFT calculations. In general terms, the evolution from the metallic-based materials to the oxide-based materials induces a decrease of density. Notice also a slight overestimation of the experimental density compared to DFT results and density estimations from XRD database (see Table 4). Concerning the elastic modulus (E), an increase can be observed with the incorporation of oxygen in the Ta metallic structures, either by experimental SAW or DFT. A general overestimation is evident in the experimental SAW results (C10F0 and C10F2), which can be attributed to an overestimation of density, since the SAW results are very sensitive to density $[26,45]$. For multilayer systems (C10F6, C10F10) the elastic modulus is ruled by the law of mixtures, combining the low $\mathrm{E}$ for the metallic rich zones with high $\mathrm{E}$ from the oxide layers. With large amounts of oxygen, the C5F13 coating reveals the lower elastic modulus and density values, which is due to the lower applied current density, and thus low deposition rate that promotes a columnar morphology.

a)

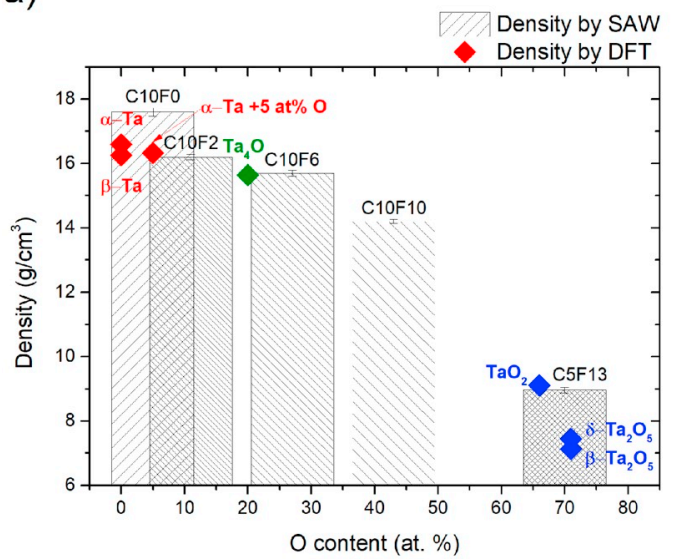

\section{Conclusions}

In this work $\mathrm{Ta}_{1-\mathrm{x}} \mathrm{O}_{\mathrm{x}}$ coatings were deposited by DC magnetron sputtering in an $\mathrm{Ar}+\mathrm{O}_{2}$ atmosphere. The formation of bcc $\alpha$-Ta phase in the non-reactive Ta coating is explained by the high substrate temperature during deposition, as demonstrated by the SIMTRA simulations. For the C10F2 coatings, when the oxygen was added (about 11 at. $\%$ ), the material transitions from an $\alpha$-Ta phase to a mixture of phases. Moreover, the value of the elastic modulus (Young's modulus) measured for C10F2 is much larger than the values achieved by DFT calculations for Ta metallic phases ( $\alpha$ and $\beta$ ). HAADF STEM, BF and PC TEM images revealed an amorphous oxide phase along the grain boundaries, which may act as a second phase causing an increase of the elastic modulus. Furthermore, an overestimation of density by SAW measurements was observed, which also led to an overestimation of the elastic modulus.

As the oxygen content was increased, the coatings became amorphous which resulted in a decrease in density and elastic modulus increase.

Ab-initio calculations are in good agreement with the experimental data and revealed that the oxygen addition to metallic Ta phase causes a decrease in density, due to a distortion of the initial structure.

b)

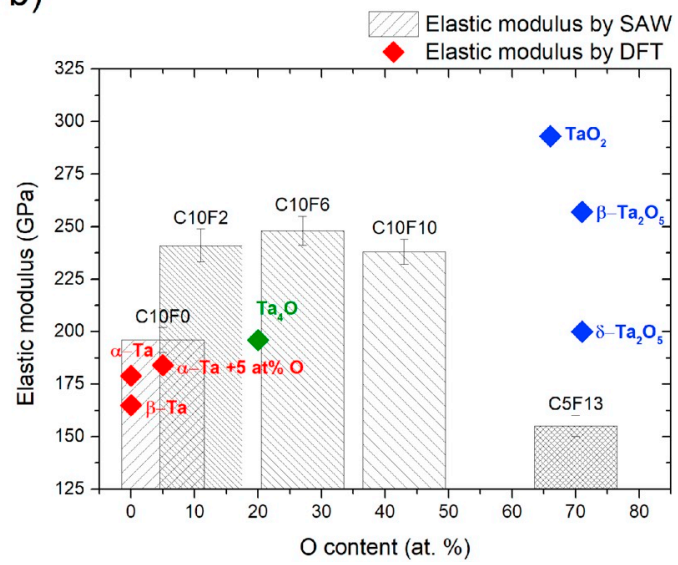

Fig. 7. Comparison of the a) density; and b) elastic modulus (Young's modulus) evolution as a function of the oxygen content increase for the SAW experimental results of the deposited coatings and the DFT calculations. 
Moreover, STEM/EDS analysis of the C10F6 and C10F10 coatings revealed a multilayer configuration for these coatings. In these cases, the elastic modulus is ruled by the law of mixtures, combining the lower $\mathrm{E}$ for the metallic rich zones and the higher $\mathrm{E}$ of the oxide layers. Finally, with large amounts of oxygen, the C5F13 coating revealed the lowest elastic modulus and density values when compared to C10F6 and $\mathrm{C} 10 \mathrm{~F} 10$, which is due to the lower applied current density during C5F13 deposition, which causes a decrease in the deposition rate.

\section{Acknowledgements}

This research is sponsored by FEDER funds through the program COMPETE - Programa Operacional Factores de Competitividade and by the Portuguese Foundation for Science and Technology (FCT) in the framework of the Strategic Funding UID/FIS/04650/2013, and UID/ EMS/00285/2013 and with a PhD fellowship SFRH/BD/98199/2013. The authors also thank the financial support in the framework of ERASIINN/0004/2013 and PTDC/CTM-NAN/4242/2014 projects.

\section{Appendix A. Supplementary data}

Supplementary data to this article can be found online at https:// doi.org/10.1016/j.surfcoat.2019.02.054.

\section{References}

[1] L. Gladczuk, A. Patel, C. Singh Paur, M. Sosnowski, Tantalum films for protective coatings of steel, Thin Solid Films 467 (2004) 150-157.

[2] A. Maho, S. Linden, C. Arnould, S. Detriche, J. Delhalle, Z. Mekhalif, Tantalum oxide/carbon nanotubes composite coatings on titanium, and their functionalization with organophosphonic molecular films: a high quality scaffold for hydroxyapatite growth, J. Colloid Interface Sci. 371 (2012) 150-158.

[3] C. Arnould, T. Korányi, J. Delhalle, Z. Mekhalif, Fabrication of tantalum oxide/ carbon nanotubes thin film composite on titanium substrate, J. Colloid Interface Sci. 344 (2010) 390-394.

[4] S. Boughaba, M. Islam, G. Sproule, M. Graham, Characterization of tantalum oxide films grown by pulsed laser deposition, Surf. Coat. Technol. 120 (1999) 757-764.

[5] H.-E. Cheng, C.-T. Mao, The effect of substrate temperature on the physical properties of tantalum oxide thin films grown by reactive radio-frequency sputtering, Mater. Res. Bull. 38 (2003) 1841-1849.

[6] K. Sasikumar, B. Narayanan, M. Cherukara, A. Kinaci, F.G. Sen, S.K. Gray, M.K.Y. Chan, S.K.R.S. Sankaranarayanan, Evolutionary optimization of a charge transfer ionic potential model for Ta/Ta-oxide heterointerfaces, Chem. Mater. 29 (2017) 3603-3614.

[7] M. Chen, X. Wang, L. Zhang, M. Yu, Q. Qin, Matrix-isolation infrared spectroscopic studies on ablated products generated from laser ablation of $\mathrm{Ta}_{2} \mathrm{O}_{5}$ and $\mathrm{Ta}$ in ambient $\mathrm{O}_{2} / \mathrm{Ar}$ gas, Chem. Phys. 242 (1999) 81-90.

[8] R. Knepper, B. Stevens, S.P. Baker, Effect of oxygen on the thermomechanical behavior of tantalum thin films during the $\beta-\alpha$ phase transformation, J. Appl. Phys. 100 (2006) 123508-123511.

[9] N.M.G. Parreira, N.J.M. Carvalho, A. Cavaleiro, Synthesis, structural and mechan ical characterization of sputtered tungsten oxide coatings, Thin Solid Films 510 (2006) 191-196.

[10] N.M.G. Parreira, N.J.M. Carvalho, F. Vaz, A. Cavaleiro, Mechanical evaluation of unbiased $\mathrm{W}-\mathrm{O}-\mathrm{N}$ coatings deposited by d.c. reactive magnetron sputtering, Surf. Coat. Technol. 200 (2006) 6511-6516.

[11] W. Yang, Y. Liu, Q. Zhang, Y. Leng, H. Zhou, P. Yang, J. Chen, N. Huang, Biomedical response of tantalum oxide films deposited by DC reactive unbalanced magnetron sputtering, Surf. Coat. Technol. 201 (2007) 8062-8065.

[12] Y. Zhou, Z. Xie, H. Xiao, P. Hu, J. He, Effects of deposition parameters on tantalum films deposited by direct current magnetron sputtering, Vacuum 83 (2009) 286-291.

[13] Y. Zhou, Z. Xie, H. Xiao, P. Hu, J. He, Effects of deposition parameters on tantalum films deposited by direct current magnetron sputtering in $\mathrm{Ar}-\mathrm{O}_{2}$ mixture, Appl. Surf. Sci. 258 (2011) 1699-1703.

[14] Y.-N. Wu, L. Li, H.-P. Cheng, First-principles studies of $\mathrm{Ta}_{2} \mathrm{O}_{5}$ polymorphs, Phys. Rev. B 83 (2011) 144105.
[15] R. Hollerweger, D. Holec, J. Paulitsch, R. Rachbauer, P. Polcik, P. Mayrhofer, Magnetic field strength influence on the reactive magnetron sputter deposition of $\mathrm{Ta}_{2} \mathrm{O}_{5}$, J. Phys. D. Appl. Phys. 46 (2013) 335203.

[16] K. Lehovec, Lattice structure of $\beta$-Ta2O5, J. Less-Common Met. 7 (1964) 397-410.

[17] X. Liu, X. Han, Z. Zhang, L. Ji, Y. Jiang, The crystal structure of high temperature phase $\mathrm{Ta}_{2} \mathrm{O}_{5}$, Acta Mater. 55 (2007) 2385-2396.

[18] N.C. Stephenson, R.S. Roth, The crystal structure of the high temperature form of Ta2O5, J. Solid State Chem. 3 (1971) 145-153.

[19] N. Stephenson, R. Roth, Structural systematics in the binary system Ta2O5-WO3. V. The structure of the low-temperature form of tantalum oxide L-Ta2O5, Acta Crystallogr. B Struct. Crystallogr. Cryst. Chem. 27 (1971) 1037-1044.

[20] S.R. Jeon, S.W. Han, J.W. Park, Effect of rapid thermal annealing treatment on electrical properties and microstructure of tantalum oxide thin film deposited by plasma-enhanced chemical vapor deposition, J. Appl. Phys. 77 (1995) 5978-5981.

[21] R. Hollerweger, D. Holec, J. Paulitsch, M. Bartosik, R. Daniel, R. Rachbauer, P. Polcik, J. Keckes, C. Krywka, H. Euchner, P.H. Mayrhofer, Complementary ab initio and X-ray nanodiffraction studies of Ta2O5, Acta Mater. 83 (2015) 276-284.

[22] M. Chandrasekhar, S. Jagadeesh Chandra, S. Uthanna, Characterization of bias magnetron sputtered tantalum oxide films for capacitors, Indian J. Pure Appl. Phys. 47 (2009) 49-53.

[23] C. Almeida Alves, C. Mansilla, L. Pereira, F. Paumier, T. Girardeau, S. Carvalho, Influence of magnetron sputtering conditions on the chemical bonding, structural, morphological and optical behavior of $\mathrm{Ta}_{1-\mathrm{x}} \mathrm{O}_{\mathrm{x}}$ coatings, Surf. Coat. Technol. 334 (2018) 105-115.

[24] C.F. Almeida Alves, S.V. Calderón, D. Dias, S. Carvalho, Influence of oxygen content on the electrochemical behavior of Ta1-xOx coatings, Electrochim. Acta 211 (2016) 385-394.

[25] C.F. Almeida Alves, A. Cavaleiro, S. Carvalho, Bioactivity response of Ta1-xOx coatings deposited by reactive DC magnetron sputtering, Mater. Sci. Eng. C 58 (2016) 110-118.

[26] D. Schneider, T. Schwarz, A photoacoustic method for characterising thin films, Surf. Coat. Technol. 91 (1997) 136-146.

[27] H. Gercek, Poisson's ratio values for rocks, Int. J. Rock Mech. Min. Sci. 44 (2007) $1-13$.

[28] J.P. Perdew, K. Burke, M. Ernzerhof, Generalized gradient approximation made simple, Phys. Rev. Lett. 77 (1996) 3865.

[29] G. Kresse, J. Furthmüller, Efficient iterative schemes for ab initio total-energy calculations using a plane-wave basis set, Phys. Rev. B 54 (1996) 11169.

[30] P.E. Blöchl, Projector augmented-wave method, Phys. Rev. B 50 (1994) 17953.

[31] G. Kresse, D. Joubert, From ultrasoft pseudopotentials to the projector augmentedwave method, Phys. Rev. B 59 (1999) 1758.

[32] H.J. Monkhorst, J.D. Pack, Special points for Brillouin-zone integrations, Phys. Rev. B 13 (1976) 5188.

[33] M. Methfessel, A. Paxton, High-precision sampling for Brillouin-zone integration in metals, Phys. Rev. B 40 (1989) 3616.

[34] P.E. Blöchl, O. Jepsen, O.K. Andersen, Improved tetrahedron method for Brillouinzone integrations, Phys. Rev. B 49 (1994) 16223.

[35] Z. Helali, M. Calatayud, C. Minot, Novel Delta-Ta2O5 structure obtained from DFT calculations, J. Phys. Chem. C 118 (2014) 13652-13658.

[36] L. Wang, T. Maxisch, G. Ceder, Oxidation energies of transition metal oxides within the GGA + U framework, Phys. Rev. B 73 (2006) 195107.

[37] R. Golesorkhtabar, P. Pavone, J. Spitaler, P. Puschnig, C. Draxl, ElaStic: a tool for calculating second-order elastic constants from first principles, Comput. Phys. Commun. 184 (2013) 1861-1873.

[38] A. Reuss, Berechnung der Fließgrenze von Mischkristallen auf Grund der Plastizitätsbedingung für Einkristalle, ZAMM Journal of Applied Mathematics and Mechanics, Z. Angew. Math. Mech. 9 (1929) 49-58.

[39] J.F. Nye, Physical Properties of Crystals: Their Representation by Tensors and Matrices, Oxford University Press, 1985, pp. P144-P145.

[40] K. Van Aeken, S. Mahieu, D. Depla, The metal flux from a rotating cylindrical magnetron: a Monte Carlo simulation, J. Phys. D. Appl. Phys. 41 (2008) 205307.

[41] J.F. Ziegler, M.D. Ziegler, J.P. Biersack, SRIM-the stopping and range of ions in matter (2010), Nucl. Instrum. Methods Phys. Res., Sect. B 268 (2010) 1818-1823.

[42] J.J. Colin, G. Abadias, A. Michel, C. Jaouen, On the origin of the metastable $\beta-T a$ phase stabilization in tantalum sputtered thin films, Acta Mater. 126 (2017) 481-493.

[43] M. Ohring, Materials Science of Thin Films, Academic Press, 2001, pp. P249-P251.

[44] M. Hans, Y.-T. Chen, K.G. Pradeep, D.M. Holzapfel, D. Primetzhofer, D. Kurapov, J. Ramm, M. Arndt, H. Rudigier, J.M. Schneider, Substrate rotation-induced chemical modulation in Ti-Al-ON coatings synthesized by cathodic arc in an industria deposition plant, Surf. Coat. Technol. 305 (2016) 249-253.

[45] D.C. Hurley, R.H. Geiss, M. Kopycinska-Müller, J. Müller, D.T. Read, J.E. Wright, N.M. Jennett, A.S. Maxwell, Anisotropic elastic properties of nanocrystalline nickel thin films, J. Mater. Res. 20 (2005) 1186-1193. 